\begin{tabular}{|c|c|c|}
\hline & $\begin{array}{c}\text { Mobilya ve Ahşap Malzeme Araştırmaları Dergisi } \\
\text { Furniture and Wooden Material Research Journal } \\
\text { Araştırma Makalesi - Research Article } \quad 2018-1(2), 94-102\end{array}$ \\
\hline
\end{tabular}

\title{
Manolya ağacı, akçaağaç ve tespih ağacı odunlarında vida tutma direnci üzerine bir araştırma
}

Vedat Çavuş $^{1 *}$, Ümit Ayata ${ }^{2}$

$\ddot{\mathbf{O z}}$

Masif odunun, mobilya üretiminde, dekorasyon işlerinde ve yap1 malzemesi olarak kullanılmasında farklı birleştirme yöntemleri kullanılmaktadır. Metal, plastik veya odundan hazırlanmış gereçler birleştirme için kullanılmaktadır. Çivi, vida, cıvata ve zımba en fazla kullanılan metal birleştirme gereçleridir. Birleştirme noktalarının mekanik performansı birleştirme gerecine ve malzemeye göre değişmektedir. Bu çalışmada, manolya (Magnolia grandiflora L.) ağacı, akçaağaç (Acer trautvetteri Medw.) ve tespih ağacı (Melia azedarach) odunlarının vida tutma direnci üç farklı yüzeyde (teğet, radyal ve enine yüzey) araştırılmıştır. Denemeler, TS EN 13446 numaralı standarda göre yapılmıştır. Denemelerde, 4 x $50 \mathrm{~mm}$ ölçülerinde çinko vida kullanılmıştır. Deneme örnekleri 50 x 50 x 50 mm (genişlik x kalınlık $\mathrm{x}$ uzunluk) ölçülerinde hazırlanmıştır. Vidalar takılmadan önce test örneklerine $2.5 \mathrm{~mm}$ çapında öndelik açılmıştır. Denemelerde vida test örneklerine $30 \mathrm{~mm}$ vidalanmıştır. Denemeler, statik malzeme test cihazında yapılmıştır. En yüksek vida tutma direnci Akçaağacın teğet yüzeyinde $\left(39.91 \mathrm{~N} / \mathrm{mm}^{2}\right)$, en düşük vida tutma direnci Tespih ağacının enine yüzeyinde $\left(24.02 \mathrm{~N} / \mathrm{mm}^{2}\right)$ belirlenmiştir. Elde edilen verilere göre; vida tutma direnci üzerine ağaç türü ve vidanın takıldığı yüzeyin önemli derecede etkili olduğu belirlenmiştir.

Anahtar kelimeler: Manolya ağacı, Akçaağaç, Tespih ağacı, Vida tutma direnci,

\section{An investigation on screw holding strength on woods of magnolia tree, maple and chinaberry tree}

\begin{abstract}
Different joining methods are used in solid wood for use in furniture production, decoration and construction materials. Materials made of metal, plastic or wood are used for joining. Nails, screws, bolts and staples are the most commonly used metal joining tools. The mechanical performance of the joining points varies depending on the joining device and the material. In this study, the screw holding resistance of magnolia (Magnolia grandiflora L.) tree, maple (Acer trautvetteri Medw.) and chinaberry tree (Melia azedarach) wood was investigated on three different surfaces (tangential, radial and transverse surface). Tests were carried out according to standard EN 13446. In the experiments, 4 x $50 \mathrm{~mm}$ zinc screw was used. Trial samples were prepared in 50 × 50 x $50 \mathrm{~mm}$ (width $\mathrm{x}$ thickness $\mathrm{x}$ length) dimensions. The test specimens were drilled for pilot hole with a diameter of $2.5 \mathrm{~mm}$ before the screws were inserted. In the trials, the screw test specimens were screwed to $30 \mathrm{~mm}$. Experiments were performed on a static material test machine. The highest screw resistance was determined in tangential surface of maple tree, and the lowest screw resistance was determined in cross-section of chinaberry tree. According to the data obtained; it was determined that the wood type and the surface, on which the screw was attached, were significantly effective on the screw holding resistance.
\end{abstract}

Keywords: Magnolia tree, Maple tree, Chinaberry tree, screw holding strength

Makale tarihçesi: Geliş:13.12.2018, Düzeltme: 23.12.2018, Kabul: 23.12.2018, Yayınlanma: 26.12.2018

Tİzmir Kâtip Çelebi Üniversitesi, Orman Fakültesi, Orman Endüstri Mühendisliği Bölümü, İzmir/Türkiye

${ }^{2}$ Atatürk Üniversitesi, Oltu Meslek Yüksekokulu, Ormancılık ve Orman Ürünleri Bölümü, Erzurum/Türkiye

*Sorumlu yazar: e-posta: vedat.cavus@ikc.edu.tr, orcid: 0000-0002-3289-7831

Atıf: Çavuş, V., ve Ayata Ü., (2018), Manolya ağacı, akçaağaç ve tespih ağacı odunlarında vida tutma direnci üzerine bir

araştırma, Mobilya ve Ahşap Malzeme Araştırmaları Dergisi, 1(2), 94-102 


\section{Giriș}

Ahşabın mobilya alanında kullanımına değer katan önemli özelliklerinden birisi de vida tutma direnci olmaktadır. Her ağaç türü farklı anatomik yapısı itibariyle farklı vida tutma direncine sahiptir. Bu konu ile ilgili olarak çeşitli araştırmalar yapılmıştır. Bunlara örnek olarak; uzunluğu $70 \mathrm{~mm}$, baş çapı $5 \mathrm{~mm}$, kök çapı $3 \mathrm{~mm}$, diş adımı $2.2 \mathrm{~mm}$ olan yıldız başlı vidaların kullanılması ile doğu kayını (Fagus orientalis Lipsky), meşe (Quercus borealis Lipsky), sarıçam (Pinus sylvestris L.), ceviz (Junglans regia) ve kestane (Castanea sativa) ağaç türlerinde enine, teğet ve radyal yüzeylerde (Çağatay ve ark., 2012), $21 * 40$ numaralı (4.5* $40 \mathrm{~mm}$ ) ağaç vidası kullanılarak sarıçam (Pinus sylvestris L.) odununda (Çelik ve ark., 2017), 21 x 40 anma boyutlarında $4.5 \mathrm{~mm}$ çap ve $40 \mathrm{~mm}$ uzunluktaki düz başl1, düşük karbonlu çelikten üretilmiş vidalar kullanılarak sakallı kızılağaç (Alnus glitunosa subsp. barbata (C.A.Mey) Yalt.), doğu kayını (Fagus orientalis Lipsky.), anadolu kestanesi (Castenea sativa Mill.), sarıçam (Pinus sylvestris L.) ve doğu ladini (Picea orientalis (L.) Link) odunlarında (Akyıldız ve Malkoçoğlu 2001), 3.5 x $50 \mathrm{~mm}$ (vida çapı x vida uzunluğu) anma ölçülerine sahip yıldız başlı çinko vidalar kullanarak doğu kayını (Fagus orientalis L.) ve melez kavak (Populus x euramericana I-214) ağaç türlerinde (Bal ve ark., 2013) vida tutma direnci belirlenmiştir. Bir başka çalışmada ise; toros sediri (Cedrus libani), uludağ göknarı (Abies bommülleriana Mattf.), kızılçam (Pinus brutia Ten.), meşe (Qercus petraea L.) ve sarıçam (Pinus sylvestris L.) ağaçlarının odunlarında, teğet, radyal ve enine yüzeylerde vida tutma direnci belirlenmiştir (Ferah 1995).

Manolya (Magnolia grandiflora L.) ağacı, tespih (Melia azedarach) ağacı ve akçaağaç (Acer trautvetteri Medw.) günümüzde farklı alanlarda değerlendirilmektedir. Manolya (Magnolia grandiflora L.) ağacı çürüme direncine karşı dayanıklı olmayıp, kaplama, kontrplak, iç kaplama, döşemeli mobilya çerçeveleri ve genel amaçlı ahşap olarak kullanılmaktadır (URL 1). Tespih (Melia azedarach) ağacının öz odunu genellikle orta derecede dayanıklı olup ve böcek saldırısına karşı biraz dirençli kabul edilmekte, oymacılıkta, kaplama üretiminde, mobilya yapımında ve tornacılık alanlarında değerlendirilmektedir (URL 2). Akçaağaç (Acer trautvetteri Medw.) ise Türkiye'de bobin ve makara imalinde, tornacilık, alet sapları, yapı malzemesi, mobilya, travers, kaplama ve kontrplak, parke ve tüfek kundağı yapımında, müzik aletleri, cetvel tahtaları, uçak pervanesi, ayakkabıcılık, ev ve süs eşyaları ile spor aletlerinde kullanılabilmektedir (Yaltırık 1970, Bozkurt ve Göker 1996, Bozkurt ve Erdin 1997).

Yapılan önceki çalışmalarda, özellikle endüstriyel olarak fazlaca kullanılan, bir çok farklı ağaç türünün, vida tutma direnci belirlenmiştir. Günümüzde, farklı bazı ağaç türlerinin odunlarının mobilya ve dekorasyon işlerinde ya da ahşap yapı sektöründe kullanıldığını bilinmektedir. Bu nedenle, bu çalışmada, daha önce vida tutma direnci üzerine bir çalışma bulunmayan, manolya ağacı, tespih ağacı ve akçaağaç türlerinde teğet, radyal ve enine yüzeylerde vida tutma dirençleri belirlenmiştir.

\section{Materyal ve Metot}

\subsection{Materyal}

$\mathrm{Bu}$ çalışmada, İzmir bölgesinde yetişmiş olan manolya (Magnolia grandiflora L.) ağacı, akçaağaç (Acer trautvetteri Medw.) ve tespih ağacı (Melia azedarach) odunları deneme materyali olarak kullanılmıştır. Test örneklerinin hazırlanması için $15 \mathrm{~cm}$ x $15 \mathrm{~cm}$ x $110 \mathrm{~cm}$ ölçülerinde laboratuar örnekleri elde edilmiştir. Sonra bu örneklerden test örnekleri 50 x 50 x $50 \mathrm{~mm}$ ölçülerinde kesilip hazırlanmıştır. 


\subsection{Metot}

\subsubsection{Rutubetin Belirlenmesi}

Manolya ağacının, akçaağacın ve tespih ağacının rutubetleri TS 2471 (1976) numaralı standarda göre belirlenmiştir. Rutubet belirlenirken, vida tutma direnci test örnekleri kullanılmıştır. Aşağıda verilen Formül (1) yardımıyla rutubet değerleri hesaplanmıştır.

$$
\mathrm{R}:\left[\left(\mathrm{m}_{\mathrm{r}}-\mathrm{m}_{0}\right) /\left(\mathrm{m}_{0}\right)\right] \times 100
$$

$\mathrm{R}:(\%)$

$\mathrm{m}_{\mathrm{r}}: \% 60 \pm 5$ bağıl nem ve $20 \pm 3{ }^{\circ} \mathrm{C}$ 'de ulaşılan değişmeyen rutubetli ağırlık (g),

$\mathrm{m}_{0}$ : Tam kuru ağırlık $(\mathrm{g})$, değerlerini ifade etmektedir.

\subsubsection{Hava Kurusu Yoğunluğun Belirlenmesi}

Manolya ağacı, akçaağaç ve tespih ağacının hava kurusu yoğunluklarının belirlenmesinde vida tutma direnci test örnekleri kullanılmıştır. TS 2472 (1976) numaralı standarda belirtilen esaslara göre yoğunluk hesaplanmıştır. Bu işlemde $\pm 0.01 \mathrm{~g}$ duyarlıklı analitik terazi yardımıyla deney örnekleri tartılmış ve deney örneklerinin boyutları $\pm 0.01 \mathrm{~mm}$ duyarlıklı kumpas ile ölçülmüştür. Daha sonra ise örneklerin hacimleri belirlenmiştir. Aşağıda verilen formül (2) yardımıyla hava kurusu yoğunlukları hesaplanmıştır.

$$
\delta_{12}:\left(\mathrm{M}_{12} / \mathrm{V}_{12}\right)\left(\mathrm{g} / \mathrm{cm}^{3}\right)
$$

Bu eşitlikte;

$\delta_{12}$ : Hava kurusu yoğunluk $\left(\mathrm{g} / \mathrm{cm}^{3}\right)$,

$\mathrm{M}_{12}$ : Hava kurusu haldeki ağırlık $(\mathrm{g})$,

$\mathrm{V}_{12}$ : Hava kurusu haldeki hacmi $\left(\mathrm{cm}^{3}\right)$, değerlerini ifade etmektedir.

\subsubsection{Vida Tutma Direncinin Belirlenmesi}

Denemelerde, vida tutma direnci, odunun üç farklı yüzeyinde (teğet, radyal ve enine yüzey) belirlenmiştir. Vida tutma direnci testleri TS EN 13446 numaralı standarda göre yapılmıştır. Denemelerde, 4 x 50 mm ölçülerinde çinko vida kullanılmıştır. Deneme örnekleri 50 x 50 x 50 mm (genişlik x kalınlık x uzunluk) ölçülerinde hazırlanmıştır (Şekil 1). Vidalar takılmadan önce test örneklerine, Bosch marka PBD40 model lazer işaretlemeli dikey matkap ile $2.5 \mathrm{~mm}$ çapında öndelik açılmıştır (Şekil 2). Denemeler yapılmadan önce test örnekleri 21 $\pm 3^{\circ}$ sıcaklık ve $\% 60 \pm 5$ bağıl nem ortamında hava kurusu hale getirilmiştir. Denemeler statik malzeme test cihazında $5 \mathrm{~m} / \mathrm{dk}$ hız ile yapılmıştır. Aşağıda verilen formül (3) ile ahşap malzemelerin vida tutma dirençleri hesaplanmıştır.

$f=\left[\left(F_{\max }\right) /\left(d \times l_{p}\right)\right] \mathrm{N} / \mathrm{mm}^{2}$

Burada;

$f=$ Vidanın geri çekilmeye karşı gösterdiği direnç $\left(\mathrm{N} / \mathrm{mm}^{2}\right)$

$l_{p}=$ Bağlayıcının girme derinliği $(\mathrm{mm})$,

$d=$ İmalâtçı tarafından verilen vida çapı (mm),

$F_{\max }=$ En büyük geri çıkma yükü $(\mathrm{N})$ 


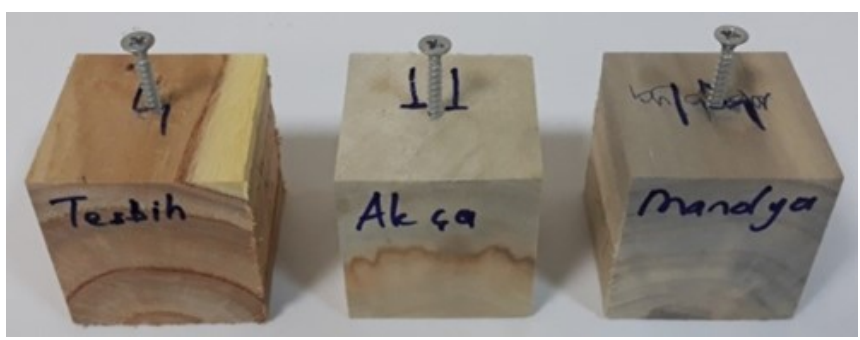

Şekil 1. Teğet yüzeyde vidalanmış deney örnekleri

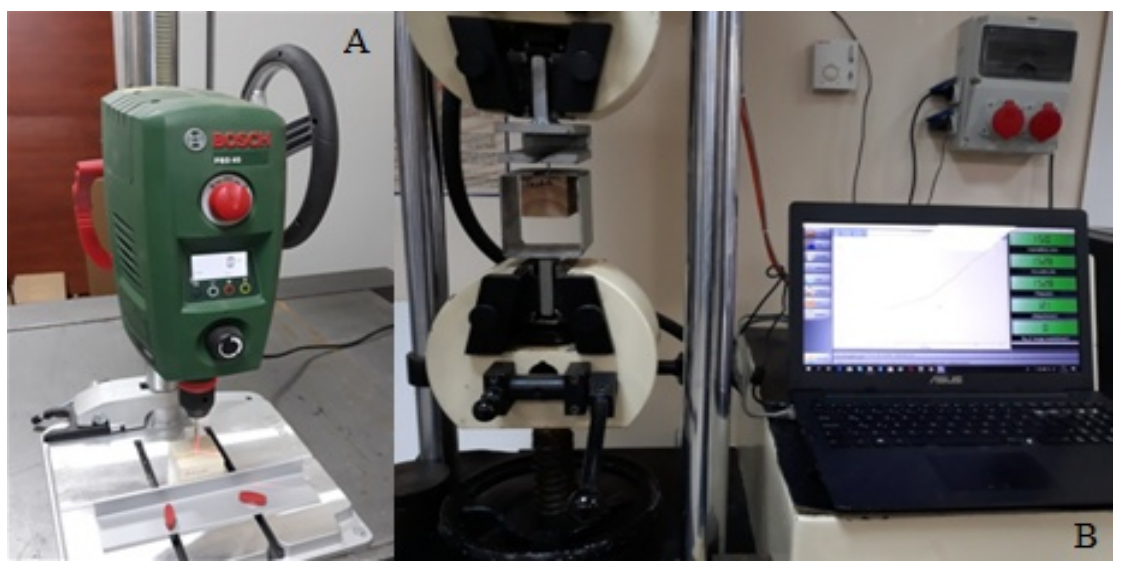

Şekil 2. Ahşap malzemelere dikey matkapta ön deliklerin açılması (A) ve Test cihazında testlerin yapilması $(\mathrm{B})$

\section{2 İstatistiksel Analiz}

$\mathrm{Bu}$ çalışmada, manolya ağacı, akçaağaç ve tespih ağacına ait odunlardan hazırlanan test örnekleri üzerinde, hava kurusu yoğunluk, hava kurusu rutubet, teğet, radyal ve enine yüzeylerde vida tutma direnci deneyleri belirlendikten sonra elde edilen veriler kullanılarak, varyans analizleri, aritmetik ortalama, standart sapma, maksimum değer ve minimum değerler, tekli ve ikili duncan testleri hesaplanmış olunup bu sonuçlar tablolar halinde sunulmuştur.

\section{Bulgular ve Tartışma}

Çizelge 1'de hava kurusu yoğunluk üzerine belirlenen varyans analizi sonuçları gösterilmektedir. Çizelge 1'e göre ağaç türü faktörü anlamsız elde edilmiştir.

Çizelge 1. Hava kurusu yoğunluk üzerine belirlenen varyans analizi sonuçları

\begin{tabular}{|c|c|c|c|c|c|}
\hline Varyasyon Kaynă̆ı & Kareler Toplamı & Serbestlik Derecesi & Ortalama Kare & F Değeri & P, $\boldsymbol{\alpha} \leq \mathbf{0 . 0 5}$ \\
\hline A ğaç Türü & 4957.733 & 2 & 2478.867 & 1.817 & $0.175^{* *}$ \\
\hline Hata & 57309.067 & 42 & 1364.502 & & \\
\hline Toplam & $1.824 \mathrm{E}+07$ & 45 & & & \\
\hline \multicolumn{5}{|l|}{$* *:$ Anlamsız } \\
\hline
\end{tabular}

Çizelge 2'de ağaç türlerine ait hava kurusu yoğunluk değerleri $\left(\mathrm{D}_{12}\right)$ verilmiştir. Çizelge 2'ye göre en düşük $D_{12}$ değeri tespih ağacı odununa ait deney örneklerinde $\left(621.67 \mathrm{~kg} / \mathrm{m}^{3}\right)$ elde edilirken, en yüksek $\mathrm{D}_{12}$ değeri manolya ağacına ait deney numunelerinde $(647.00$ $\mathrm{kg} / \mathrm{m}^{3}$ ) belirlenmiştir. Yoğunluk ve rutubet masif odunun mekanik özelliklerini belirleyen önemli fiziksel özelliklerdir. Yoğunluğun etkisi rutubetin etkisinden daha yüksektir. Yoğunluğun değişmesi ile odunun çalışması (daralma-genişleme) ve lif doygunluk noktası 
gibi fiziksel özellikleri değişmektedir (Kollman ve Cote 1968; Bozkurt ve Göker 1996; Bal ve Bektaş 2018) Masif odunda genel olarak, rutubet arttıkça ve yoğunluk azaldıkça, mekanik özellikler azalmaktadır. Bunun aksine, rutubet azaldıkça ve yoğunluk arttıkça mekanik özellikler artmaktadır. Yoğunluk arttıkça vida tutma direnci artmaktadır (Bal ve ark. 2013, Bal ve ark., 2016). Bu ilişkiyi etkileyen faktörler ise özellikle iğne yapraklı ağaçlarda reçinenin varlığı ve rutubet yüzdesinin lif doygunluk noktası üzerine çıkmasıdır. Bal ve ark., (2012) tarafından sedir odunu üzerinde yapılan çalışmada, yoğunluğun artması ile doğrusal bir şekilde mekanik özelliklerin artmamasının nedeninin reçine olduğu bildirilmiştir. Lif doygunluk noktasına kadar, rutubet miktarının artması ile mekanik özelliklerin azaldığı birçok çalışmada not edilmiştir (Kollman ve Cote 1968, Bozkurt ve Göker 1996).

Çizelge 2. Ağaç türlerine ait hava kurusu yoğunluk değerleri $\left(\mathrm{D}_{12}\right)$

\begin{tabular}{|c|c|c|c|c|c|c|}
\hline Ağaç Türü & $\begin{array}{l}\text { Ölçüm } \\
\text { Sayısı }\end{array}$ & $\frac{\mathrm{D}_{12}}{\left(\mathrm{~kg} / \mathrm{m}^{3}\right)}$ & HG & SS & $\begin{array}{c}\text { Minimum } \\
\text { Ölçüm }\left(\mathbf{k g} / \mathbf{m}^{3}\right)\end{array}$ & $\begin{array}{l}\text { Maksimum } \\
\text { Ölçüm }\left(\mathbf{k g} / \mathbf{m}^{3}\right)\end{array}$ \\
\hline $\begin{array}{c}\text { Manolya Ağacı } \\
\text { (Magnolia grandiflora L.) }\end{array}$ & 15 & 647.00 & $A^{*}$ & 63.30 & 532.00 & 719.00 \\
\hline $\begin{array}{c}\text { Akçaağaç } \\
\text { (Acer trautvetteri Medw.) }\end{array}$ & 15 & 638.13 & A & 5.46 & 630.00 & 650.00 \\
\hline $\begin{array}{c}\text { Tespih A Agacı } \\
(\text { Melia azedarach })\end{array}$ & 15 & 621.67 & $A^{* *}$ & 7.51 & 603.00 & 634.00 \\
\hline
\end{tabular}

Çizelge 3'de hava kurusu yoğunluk üzerine belirlenen varyans analizi sonuçları gösterilmektedir. Çizelge 3 incelendiği zaman ağaç türü faktörünün anlamlı olarak elde edildiği görülmektedir.

Çizelge 3. Rutubet üzerine belirlenen varyans analizi sonuçları

\begin{tabular}{|c|c|c|c|c|c|}
\hline Varyasyon Kaynă̆ı & Kareler Toplamı & Serbestlik Derecesi & Ortalama Kare & F Değeri & P, $\boldsymbol{\alpha} \leq \mathbf{0 . 0 5}$ \\
\hline A ğaç Türü & 2.242 & 2 & 1.121 & 9.063 & $0.001^{*}$ \\
\hline Hata & 5.195 & 42 & 0.124 & & \\
\hline Toplam & 7693.25 & 45 & & & \\
\hline \multicolumn{5}{|c|}{ *: Anlamlı } \\
\hline
\end{tabular}

Çizelge 4'de ağaç türlerine ait rutubetlere ait sonuçlar gösterilmektedir. En yüksek rutubet tespih ağacinda (\% 13.34) bulunurken, bunu akçaağaç (\% 13.07) ve manolya ağacı (\% 12.79) takip etmiştir (Çizelge 4). Çizelge 4 'de verilen bulgular incelendiği zaman, ağaç türleri için rutubet değerlerinin \% 12 rutubet seviyesine oldukça yakın oldukları görülmektedir. Ayrıca, ölçülen denge rutubeti yüzdelerinin birbirlerine çok yakın olduğu görülmektedir. $\mathrm{Bu}$ nedenle elde edilen vida tutma direncine ait bulgular arasındaki farkların rutubetten kaynaklandığı düşünülemez. Farklı Rutubet yüzdelerine sahip test örneklerinin mekanik özellikleri arasında farklar oluşabilir. Ancak bu belirgin rutubet farklılıklarında ortaya çıkmaktadır. Örneğin, Bal (2016) kontrplak test örnekleri üzerinde yapmış olduğu çalışmada bunu \%10 rutubet farklılığı için belirlemiştir. Benzer bir çalışmada, kayın, kızılağaç, kestane, ladin ve sarıçam odun örneklerinde rutubetin ve ağaç türünün vida tutma direnci üzerine etkisi araştırılmış ve en yükssek vida tutma direnci denemelerde kullanılan en yüksek yoğunluğa sahip kayın odununda elde edilmiş ve rutubet artışının vida tutma direncini düşürdüğü belirlenmiştir (Akyıldız ve Malkoçoğlu 2001). 
Çizelge 5'de vida tutma direnci üzerine varyans analizi sonuçları verilmiştir. Çizelge 5'e göre, ağaç türü (A) ve vidama yüzeyi (B) faktörleri anlamlı elde edilirken, bu faktörlerin etkileşimi (AB) anlamsız olarak belirlenmiştir ( $\alpha \leq 0.05$ 'e göre).

Çizelge 4. Ağaç türlerine ait rutubet sonuçları

\begin{tabular}{|c|c|c|c|c|c|c|}
\hline Ağaç Türü & $\begin{array}{l}\text { Ölçüm } \\
\text { Sayısı }\end{array}$ & $\begin{array}{c}\text { Ortalama Rutubet } \\
(\%) \\
\end{array}$ & HG & SS & $\begin{array}{l}\text { Minimum } \\
\text { Ölçüm (\%) }\end{array}$ & $\begin{array}{l}\text { Maksimum } \\
\text { Ölçüm (\%) }\end{array}$ \\
\hline $\begin{array}{c}\text { Manolya Ağacı } \\
\text { (Magnolia grandiflora L.) }\end{array}$ & 15 & 12.79 & $\mathrm{C}^{* *}$ & 0.31 & 11.90 & 13.10 \\
\hline $\begin{array}{c}\text { Akçaağaç } \\
\text { (Acer trautvetteri Medw.) }\end{array}$ & 15 & 13.07 & B & 0.47 & 12.60 & 14.60 \\
\hline $\begin{array}{c}\text { Tespih Ağacı } \\
(\text { Melia azedarach })\end{array}$ & 15 & 13.34 & $A^{*}$ & 0.23 & 13.00 & 13.70 \\
\hline
\end{tabular}

Çizelge 5. Vida tutma direnci üzerine varyans analizi sonuçları

\begin{tabular}{|c|c|c|c|c|c|}
\hline Varyasyon Kaynağı & Kareler Toplamı & Serbestlik Derecesi & Ortalama Kare & F Değeri & P, $\boldsymbol{\alpha} \leq \mathbf{0 . 0 5}$ \\
\hline Ăgaç Türü (A) & 1004.652 & 2 & 502.326 & 32.157 & $0.000^{*}$ \\
\hline Vidalama Yüzeyi (B) & 1710.033 & 2 & 855.017 & 54.735 & $0.000^{*}$ \\
\hline Etkileşim (AB) & 136.485 & 4 & 34.121 & 2.184 & $0.074 * *$ \\
\hline Hata & 1968.263 & 126 & 15.621 & & \\
\hline Toplam & 156122.250 & 135 & & & \\
\hline \multicolumn{7}{|l}{ *: Anlamlı, **: Anlamsız } \\
\hline
\end{tabular}

Çizelge 6'da ağaç türü ve vidalama yüzeyinde tekli Duncan testi karşılaştırma sonuçları verilmiştir. Çizelge 6'ya göre, ağaç türü düzeyinde en yüksek vida tutma direnci akçaağaç odununa ait örneklerde $\left(36.66 \mathrm{~N} / \mathrm{mm}^{2}\right)$ tespit edilirken, bunu sırası ile manolya ağacı $(33.78$ $\left.\mathrm{N} / \mathrm{mm}^{2}\right)$ ve tespih ağacı $\left(30.00 \mathrm{~N} / \mathrm{mm}^{2}\right)$ izlemiştir. Vidalama yüzeyi düzeyinde ise en yüksek vida tutma direnci teğet $\left(37.99 \mathrm{~N} / \mathrm{mm}^{2}\right)$ yüzeyde elde edilirken, bunu radyal $\left(33.36 \mathrm{~N} / \mathrm{mm}^{2}\right)$ ve enine $\left(29.29 \mathrm{~N} / \mathrm{mm}^{2}\right.$ ) yüzeyler izlemiştir (Çizelge 6). Bunun en önemli nedenlerinin ise teğet yüzeyde yapılan vida testi esnasında yıllık halkaların vidaların çıkmasını önleyen birer bariyer olarak görev yapması ve enine kesitte odun hücrelerinin bir birinden ayrılmasının daha kolay olmasıdır denebilir. Benzer bir çalışmada, Kılıç ve ark., (2007) ceviz, göknar, meşe ve kiraz ağaçlarının odunlarının teğet, radyal ve enine kesit yüzeylerinde vida ve çivi tutma direnci testleri uygulamışlar ve benzer sonuçlar elde etmişlerdir. Bir başka çalışmada Gasparic ve ark., (2015) tarafından Avrupa ladini odunu üzerinde yapılmıştır. Bu çalışma sonuçlarında göre en yüksek vida tutma direnci teğet yüzeyde (radyal yönde) elde edilmiştir. Örs ve ark., (1998) tarafından yapılan çalışmada, vida tutma direnci üzerine, ön delik çapı, vida çapı, yüzey (paralel-dik) tutkal kullanılması gibi faktörlerin etkisi olduğu gösterilmiştir. Bir başka çalışmada ise, ön delik çapı, vida tipi ve lamine ahşap malzemenin katman kalınlığının vida tutma direnci üzerine etkisi belirlenmiştir (Özçiftçi 2009).

Çizelge 6. Ağaç türü ve vidalama yüzeyine ait tekli Duncan testi karşılaştırma sonuçları

\begin{tabular}{|c|c|c|c|}
\hline Ăgaç Türü & Ölçüm Sayısı & Aritmetik Ortalama $\left(\mathrm{N} / \mathrm{mm}^{2}\right)$ & HG \\
\hline Manolya Ağacı (Magnolia grandiflora L.) & 45 & 33.78 & $\mathrm{~B}$ \\
\hline Akçaağaç (Acer trautvetteri Medw.) & 45 & 36.66 & $\mathrm{~A}^{*}$ \\
\hline Tespih Ağacı (Melia azedarach) & 45 & 30.00 & $\mathrm{C}^{* *}$ \\
\hline Vidanın takıldığı yüzey & Ölçüm Sayısı & Aritmetik Ortalama $\left(\mathrm{N} / \mathrm{mm}^{2}\right)$ & HG \\
\hline Teğet & 45 & 37.99 & $A^{*}$ \\
\hline Radyal & 45 & 33.36 & $\mathrm{~B}$ \\
\hline Enine & 45 & 29.29 & $\mathrm{C}^{* *}$ \\
\hline
\end{tabular}


Çizelge 7'de ağaç türü - vidalama yüzeyi ikili etkileşimine ait Duncan karşılaştırma sonuçları verilmiştir. Çizelge 7'ye göre, en yüksek vida tutma direnci akçaağaç odununun teğet yüzeyinde yapılan örneklerinde $\left(39.91 \mathrm{~N} / \mathrm{mm}^{2}\right)$ elde edilirken, en düşük vida tutma direnci tespih ağacı odununun teğet yüzeyinde yapılan örneklerinde $\left(24.02 \mathrm{~N} / \mathrm{mm}^{2}\right)$ belirlenmiştir. Bütün ağaç türlerinde yapılan vida tutma direnci büyükten küçüğe doğru en yüksek teğet yüzeylerde sonra raydal yüzeylerde ve en son enine yüzeylerde olacak şekilde bulunmuştur.

Çizelge 7 incelendiğinde, en düşük yoğunluğa sahip olan tespih odununun en düşük vida tutma direncine sahip olduğu görülmektedir. Diğer iki ağaç türünün yoğunluğu birbirine yakındır. Manolya odununun vida tutma direnci akçaağaç odunundan yoğunluğu biraz yüksek olmasına rağmen daha düşük ölçülmüştür. Bunun sebebinin ise odunun hücre yapısından ve lignin miktarından kaynaklandığı söylenebilir. Bazı odunlarda öz ışını paranşim hücreleri miktarı diğer hücre tiplerine göre daha fazla bulunmaktadır. Bunun doğal sonucu olarak odunun yapısı daha girift bir hal olmaktadır. Liflere paralel yönde yarılma direnci artmaktadır. Daha sıkı bir odun yapısı oluşmaktadır. Lignin miktarının artması ile hücrelerin birbirlerine bağlanma kuvveti de artmaktadır. Bunun gibi nedenlerle farklı ağaç odunlarının yoğunlukları benzer olsa dahi mekanik özellikleri arasında farklılıklar oluşmaktadır. Benzer çalışmalarda elde edilen sonuçlar bu çalışmada elde edilen sonuçları doğrulamaktadır (Taj ve ark., 2009, Çağatay ve ark., 2012).

Çizelge 7. Ağaç türü - vidalama yüzeyi ikili etkileşimine ait Duncan karşılaştırma sonuçları

\begin{tabular}{|c|c|c|c|c|c|c|c|}
\hline Ağaç Türü & $\begin{array}{c}\text { Vidanın takıldığı } \\
\text { Yüzey }\end{array}$ & $\begin{array}{l}\text { Ölçüm } \\
\text { Sayısı }\end{array}$ & $\begin{array}{c}\text { Aritmetik } \\
\text { Ortalama } \\
\left(\mathbf{N} / \mathbf{m m}^{2}\right) \\
\end{array}$ & HG & SS & $\begin{array}{l}\text { Minimum } \\
\text { Ölçüm } \\
\left(\mathbf{N} / \mathbf{m m}^{2}\right) \\
\end{array}$ & $\begin{array}{c}\text { Maksimum } \\
\text { Ölçüm } \\
\left(\mathbf{N} / \mathbf{m m}^{2}\right)\end{array}$ \\
\hline \multirow{3}{*}{$\begin{array}{l}\text { Manolya Ağacı } \\
\text { (Magnolia } \\
\text { grandiflora L.) }\end{array}$} & Teğet & 15 & 38.40 & $\mathrm{AB}$ & 6.61 & 25.20 & 47.20 \\
\hline & Radyal & 15 & 32.53 & $\mathrm{DE}$ & 4.40 & 26.10 & 43.40 \\
\hline & Enine & 15 & 30.40 & $\mathrm{E}$ & 4.72 & 23.80 & 40.00 \\
\hline \multirow{3}{*}{$\begin{array}{c}\text { Akçaağaç } \\
\text { (Acer trautvetteri } \\
\text { Medw.) }\end{array}$} & Teğet & 15 & 39.91 & $\mathrm{~A}^{*}$ & 1.97 & 34.60 & 42.60 \\
\hline & Radyal & 15 & 36.63 & $\mathrm{~B}$ & 2.78 & 31.50 & 40.80 \\
\hline & Enine & 15 & 33.45 & $\mathrm{CD}$ & 3.50 & 22.90 & 37.70 \\
\hline \multirow{3}{*}{$\begin{array}{c}\text { Tespih Ağacı } \\
\text { (Melia azedarach) }\end{array}$} & Teğet & 15 & 35.66 & $\mathrm{BC}$ & 0.81 & 34.30 & 36.80 \\
\hline & Radyal & 15 & 30.31 & $\mathrm{E}$ & 4.38 & 22.20 & 37.00 \\
\hline & Enine & 15 & 24.02 & $\mathrm{~F}^{* *}$ & 3.38 & 20.50 & 31.90 \\
\hline
\end{tabular}

\section{Sonuçlar ve Öneriler}

$\mathrm{Bu}$ çalışmada, manolya ağacı, akçaağaç ve tespih ağacı türlerinin odunlarından elde edilen test örneklerinin teğet, radyal ve enine kesit yüzeylerinde vida tutma direnci testleri gerçekleştirilmiştir. Elde dilen bulgulara göre şu sonuçlar söylenebilir:

- $\quad$ Ağaç türü, vida tutma direnci üzerine istatistiksel olarak önemli seviyede etkilidir. Özellikle yoğunluğu yüksek olan türlerin vida tutma direnci daha yüksektir.

- $\quad$ Odunun üç temel yönünün, diğer mekanik özelliklerde olduğu gibi, vida tutma direnci üzerine de etkisi vardır. Odunun vida tutma direnci, bu üç temel yünde farklılık göstermektedir. Bu çalışma sonunda elde edilen verilere göre; vida tutma direncinin her üç yönde birbirinden farklı olduğu tespit edilmiştir. En yüksek vida tutma direnci teğet yönde belirlenmiştir. En düşük ise enine yüzeyde belirlenmiştir. 


\section{Kaynaklar}

Akyıldız, M. H., ve Malkoçoğlu, A., (2001), Doğu Karadeniz bölgesinde yetişen önemli bazı ağaç odunlarının vida tutma dirençleri, Artvin Orman Fakültesi Dergisi, 2(1), 54-60.

Bal, B.C., Bektaş, İ., ve Kaymakçı, A., (2012), Toros sedirinde genç odun ve olgun odunun bazı fiziksel ve mekanik özellikleri, KSU Mühendislik Bilimleri Dergisi,15(2), 17-27.

Bal, B.C., Özdemir, F., ve Altuntaş, E, (2013), Masif ağaç malzeme ve tabakalı kaplama kerestenin vida tutma direnci üzerine karşılaştırmalı bir çalışma, Düzce Üniversitesi Ormancilık Dergisi, 9(2), 14-22.

Bal, B.C., (2016), The effect of moisture content on the screw holding capacity of birch and pine plywood, International Forestry Symposium-IFS2016, 7-10 December 2016, Procedings books P: 1020-1026, Kastamonu.

Bal, B.C., Akçakaya, E., Gündeş, E., (2016), Farklı ağaç türlerinden üretilmiş kontrplakların yanal çivi dayanımı üzerine bir araştırma, Düzce Üniversitesi, Ormancılık Dergisi, 12(1), 145-153.

Bal BC, Bektaş İ, (2018), Kayın ve Kavak odunlarında fiziksel özelliklerle yoğunluk ilişkisinin belirlenmesi, Mobilya ve Ahşap Malzeme Araştırmaları Dergisi, 1(1), 1-10.

Bozkurt, Y., ve Göker, Y., (1996), Fiziksel ve Mekanik Ağaç Teknolojisi, İ.Ü., Orman Fakültesi Yayınları, Üniversite Yayın No: 3944, İstanbul.

Bozkurt, A.Y., ve Erdin, N., (1997), Ağaç Malzeme Teknolojisi Ders Kitabı, İstanbul Üniversitesi Yayın No: 3998, Fakülte Yayın No: 445, ISBN 975-404-449-X.

Çağatay, K., Efe, H., Burdurlu, E., ve Kesik, H. İ., (2012). Bazı ağaç malzemelerin vida tutma mukavemetlerinin belirlenmesi, Kastamonu Üniversitesi, Orman Fakültesi Dergisi, 12(2), 321-328.

Çelik, İ., Yılmaz, H., Bideci, A., (2017), Sarıçam ağaç odunlarının çivi ve vida tutma dirençlerinin belirlenmesi üzerine bir araştırma, Illeri Teknoloji Bilimleri Dergisi, 6(3), 360-368.

Ferah, O., (1995). Bazı önemli ağaç türlerimizin vida ve çivi tutma direnç özelliklerinin belirlenmesi, Ormancılık Araştırma Enstitüsü Yayınları, Teknik bülten No:252.

Gašparík, M., Barcík, Š., Borůvka, V., Holeček, T., (2015), Impact of thermal modification of spruce wood on screw direct withdrawal load resistance, BioResources, 10(1), 17901802.

Kılıç, M., Burdurlu, E., Usta, I., Berker, U. Ö., and Oduncu, P., (2007), Comparative analysis of the nail and screw withdrawal resistances of fir (Abies Mill.), cherry (Prunus Avium L.), walnut (Juglans Regia L.) and oak (Quercus L.) wood,Düzce Üniversitesi Ormancilık Dergisi, 2(2), 61-75.

Kollmann, F.F., Cote Jr W.A., (1968), Principles of wood science and technology. vol. I. Solid Wood, In Principles of Wood Science and Technology, Vol. I. Solid Wood, Springer-Verlag.

Özçifçi, A., (2009), The effects of pilot hole, screw types and layer thickness on the withdrawal strength of screws in laminated veneer lumber, Materials \& Design, 30(7), 2355-2358. 
Taj, M. A., Najafi, S. K., and Ebrahimi, G., (2009), Withdrawal and lateral resistance of wood screw in beech, hornbeam and poplar, European Journal of Wood and Wood Products, 67(2), 135-140.

TS 2471, (1976), Odunda fiziksel ve mekaniksel deneyler için rutubet miktarı tayini, Türk Standartları Enstitüsü, Ankara.

TS 2472, (1976), Odunda fiziksel ve mekaniksel deneyler için birim hacim ağırlığı tayini, Türk Standartları Enstitüsü, Ankara.

TS EN 13446, (2005), Ahşap esaslı levhalar - bağlayıcıların geri çıkma kapasitesinin tayini, Türk Standartları Enstitüsü, Ankara.

URL 1. Manolya (Magnolia grandiflora L.) Ağacı Hakkında Bazı Bilgiler, https://www.wood-database.com/southern-magnolia/, (11.09.2018)

URL 2. Tespih Ağacı (Melia azedarach) Ağacı Hakkında Bazı Bilgiler, https://www.wooddatabase.com/chinaberry/, (11.09.2018)

Yaltırık, F., (1970), Türkiye'de akçaağaçların kullanılışı ve değerlendirilmesi imkânlarının irdelenmesi, İ.Ü. Orman Fakültesi Dergisi, 20(1), 29-33. 